\title{
COMPARATIVE STUDY OF CAST IMMOBILIZATION OF WRIST IN FUNCTIONAL POSITION VERSUS CONVENTIONAL PALMAR FLEXION IN COLLES' FRACTURE
}

Shriraj Shrestha ${ }^{1, *}$, Parash Bhandari', Saurav Dahal', Basanta Maharjan', Suraj Bajracharya'

${ }^{1}$ Department of Orthopaedics and Trauma, KIST Medical College and Teaching Hospital, Imadol, Lalitpur, Nepal

Received: 7 Apr, 2020
Accepted: 23 Aug, 2020
Published: 27 Sept, 2020
Key words: Cast immobilization; Colles' fracture; Dorsi-
flexion; Palmar flexion.
*Correspondence to: Shriraj Shrestha, Department of
Orthopaedics and Trauma, KIST Medical College and
Teaching Hospital, Imadol, Lalitpur, Nepal
\[ \text { Email: shrirajshrestha@gmail.com } \]
Citation
Shrestha S, Bhandari P. Dahal S, Maharjan B, Bajra-
charya S. Comparative study of cast immobilization
of wrist in functional position versus conventional
palmar flexion in colles' fracture. Journal of Chit-
wan Medical College.2020;10(33):47-52.

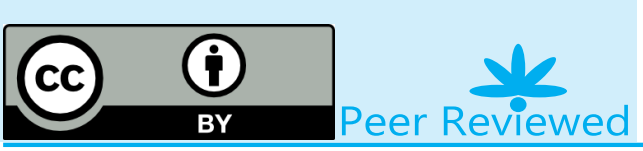

INTRODUCTION

Colles' fracture is one of the commonest fractures in the elderly age group as described by Sir Abraham Colles in 1814 in Edinburg medical journal. ${ }^{1}$ Colles' fracture and osteoporosis show a direct relation and result from low energy trauma, therefore this type of fractures are commonly seen in the peri and postmenopausal age group.

Both conservative and operative treatment modalities are available for treating Colles' fractures. Among them, close reduction and cast application can be adopted at a lower cost with an almost uniformly good result as compared to expensive operative modalities. ${ }^{2}$ In the conservative treatment of Colles' fractures, the usual practice is to immobilize the wrist in palmar flexion and ulnar deviation. ${ }^{1}$ But this position has a risk of causing stiffness of the fingers and wrist. ${ }^{3}$ Contrary to it, dorsiflexion is regarded as the best functional position for hand. ${ }^{4}$

Numerous previous studies have considered displacement of the fractures, but very few have worked on the role of the position of immobilization as a parameter for comparing radiological and functional outcomes. Thus the rationale of the study was to estimate the functional and radiological outcome of
Colles' fracture treated with wrist immobilized in dorsiflexion ( DF ) and palmar flexion ( PF ) position as there is a paucity of local literature on this topic.

This study aimed to assess and compare the functional and radiological outcomes using the Demerit Scoring System of Saito for wrist immobilized in functional (dorsiflexion) and palmar flexion position, after reduction of Colles' fracture.

\section{METHODS}

This was a hospital-based observational study, conducted from April 2019 to March 2020 in the Orthopedics and Emergency department of KIST Medical College Teaching Hospital, Lalitpur, Nepal. Ethical approval clearance was taken from the institutional review committee KISTMCTH (registration number 2075/76/72). Convenience sampling was done and 62 patients, 31 in each group were identified with age 45 years and above who presented within 7 days of trauma with extra-articular fractures of Frykman category I and II (Colles type only) with or without ulna styloid process fracture were included in this study. All intra-articular fractures, open fractures, pathological fractures, previous fracture in the same 
Table 1: Demerit point system (Saito) ${ }^{9}$

\begin{tabular}{|c|c|c|}
\hline \multicolumn{3}{|c|}{ Demerit point system (Saito) } \\
\hline Subjective Evaluation & & Points \\
\hline Excellent & no pain, no disability, no limitation of motion & 0 \\
\hline Good & occasional pain, no disability, slightly limitation of motion & 2 \\
\hline Fair & occasional pain, no particular disability if careful, some limitation of motion, feeling of weakness in wrist, activities slightly restricted & 4 \\
\hline Poor & pain, disability, limitation of motion, activities markedly restricted & 6 \\
\hline \multicolumn{3}{|l|}{ Objective Evaluation } \\
\hline I. Residual Deformity & out of the range of & \\
\hline Ulnar variance & $0 \pm 2 \mathrm{~mm}$ & 1 \\
\hline Palmar tilt & $11^{\circ} \pm 10^{\circ}$ & 1 \\
\hline Radial tilt & $23^{\circ} \pm 10^{\circ}$ & 1 \\
\hline \multicolumn{3}{|l|}{ II. Range of Motion } \\
\hline Dorsiflexion & $<45^{\circ}$ & 1 \\
\hline Palmar flexion & $<30^{\circ}$ & 1 \\
\hline Ulnar flexion & $<15^{\circ}$ & 1 \\
\hline Radial flexion & $<15^{\circ}$ & 1 \\
\hline Supination & $<50^{\circ}$ & 1 \\
\hline Pronation & $<50^{\circ}$ & 1 \\
\hline \multicolumn{3}{|l|}{ III. Grip Power } \\
\hline \multirow{2}{*}{ Dominant hand } & $<$ the power of the opposite hand & 1 \\
\hline & $<2 / 3$ of the power of the opposite hand & 2 \\
\hline \multirow{2}{*}{ Non-dominant hand } & $<2 / 3$ of the power of the opposite hand & 1 \\
\hline & $<1 / 2$ of the power of the opposite hand & 2 \\
\hline \multicolumn{3}{|l|}{ IV. Arthritic Change } \\
\hline None & & 0 \\
\hline Minimal & irregularity of the articular surface, sharpening of the articular margin & 1 \\
\hline Moderate & narrowed joint space; osteophyte & 2 \\
\hline Severe & marked osteophyte formation; ankylosis & 3 \\
\hline \multicolumn{3}{|l|}{ Complication } \\
\hline Nerve complication & & $1-2$ \\
\hline Stiff fingers & & $1-2$ \\
\hline Rupture tendons & & $1-2$ \\
\hline End Result & & Point range \\
\hline Excellent & & $0-3$ \\
\hline Good & & $4-9$ \\
\hline Fair & & $10-15$ \\
\hline Poor & & $16-26$ \\
\hline
\end{tabular}

wrist, and patients with polytrauma, neurovascular involvement, and who did not appear in twelve weeks follow-up were excluded from the study.

Thorough history with demographic details, injured side, dominant hand, mechanism of injury, clinical examination, and radiograph of the injured wrist in posteroanterior and lateral views was documented. All the patients were explained about the procedures to be performed and written consent was obtained. Depending upon the swelling, patients were initially treated with below elbow plaster of Paris (POP) slab for approximately five days followed by closed reduction and below elbow cast application or direct manipulation and cast application under hematoma block (1\% lignocain without adrenalin, water for injection and $10 \mathrm{ml}$ disposable syringe). ${ }^{5}$

Hematoma block was given after a skin sensitivity test from the dorsal aspect (amount according to body weight 3-5 mg/ $\mathrm{kg}$ ), after which reduction of fractures was carried out by applying longitudinal traction, palmar flexion, and ulnar deviation at the fracture site. Once the fracture got reduced as seen under $\mathrm{C}$-arm, the patients were allocated below-elbow 
cast with the wrist in Dorsiflexed (DF) or Palmar flexed (PF) attitude alternatively. The degree of immobilization at the wrist was either $15^{\circ}$ Dorsiflexion or $15^{\circ} \mathrm{Palmar}$ flexion, maintaining palmar flexion and ulnar deviation at the fracture site in both the groups during molding. ${ }^{6}$

Patients with no intra-procedure complications were discharged on the same evening after a check X-ray and explained the known plaster related complications. ${ }^{6}$ Rehabilitation was started as soon as possible with an active finger, elbow, and shoulder movement. A total of three follow-ups were made, the first follow up was done at one week after the manipulation with an X-ray to measure the radiological parameters. Any loss of reduction during that period were excluded from the study and opted for surgery. Figure 1 shows guidelines for acceptable reduction of Colles' fracture.

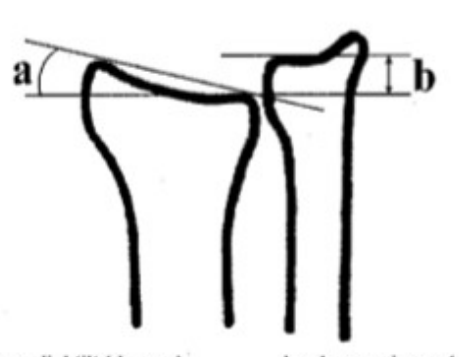

a: radial tilt (degree)

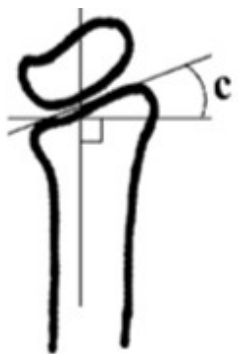

c: palmar tilt (degree)
Figure 1: Measurement used for the radiological results ${ }^{7,8}$ : a. Radial tilt in postero- anterior radiograph $23^{\circ} \pm 10^{\circ}$, b.UInar variance $0 \pm 2 \mathrm{~mm}, \mathrm{c}$. Palmar tilt in lateral projection $11^{\circ} \pm 10^{\circ}$

The subsequent follow-ups were planned on the $6^{\text {th }}$ and $12^{\text {th }}$ weeks. Plaster removal was done in the $6^{\text {th }}$ week followed by both active and passive exercise of fingers and wrist with the help of a physiotherapist.

During the last two follow-ups, functional results were determined using the Demerit point system of Saito. ${ }^{7,9}$ This system consisted of subjective evaluation, objective evaluation, and complications. One or more point was given if any of the parameters showed an abnormal range. Range of motion was measured using a goniometer and grip strength was taken by using a sphygmomanometer which was rolled and inflated to $20 \mathrm{~mm}$ of $\mathrm{Hg}$. Thereafter, the patient had to squeeze and the pressure achieved was recorded. Readings were taken from both the injured and uninjured hands for comparison. ${ }^{10}$ All these subjective evaluations, objective evaluations, and complications were calculated and graded using the Demerit scoring system of Saito at $6^{\text {th }}$ and $12^{\text {th }}$ weeks showing excellent 0-3, good 4-9, fair 10-15, and poor 16-26.

Data was entered using statistical package for social science version 16 and, the analysis was carried out using descriptive and inferential statistics. A p-value of less than 0.05 was considered statistically significant.

\section{RESULTS}

There were 62 patients eligible for the study, with 31 in each group. Female patients were more than male patients 43 $(69.4 \%)$ and $19(30.6 \%)$ respectively. The mean age of the pa- tients was $63.2 \pm 10.6$. The trivial injury was the major cause of Colles' fracture accounting for $46(74.2 \%)$ patients as compared to $16(25.8 \%)$ patients with a road traffic accident. The majority of the patients 59 (95.1\%) were right-handed and only $3(4.8 \%)$ patients were left-handed. Regarding the fracture side, 40 (64.5\%) patients had left side fracture and 22 $(35.4 \%)$ patients had right side fracture.

The functional results at twelve weeks of follow-up were as follows:

All $31(100 \%)$ patients in the DF group had more than or equal to $45^{\circ}$ of dorsiflexion as compared to $13(42 \%)$ patients in the PF group ( $p<0.001)$, likewise palmar flexion of $30^{\circ}$ or more were present in all the patients of both DF and PF groups ( $p$ $<0.001)$. Supination and pronation of $50^{\circ}$ or more were observed in $27(87.1 \%)$ and 31 (100\%) patients in DF group respectively, and 9 (29.1\%) and 24 (77.5\%) patients in PF group respectively $(p<0.001)$.

Radial deviation of $15^{\circ}$ or more was achieved in 27 (87.1\%) patients in the DF group and 23 (74.2\%) patients in the PF group ( $p=0.042)$, similarly all the patients in both the groups could ulna deviate the wrist to $15^{\circ}$ or more $(p=0.687)$. As compared to the uninjured hand, grip power was normal in the fractured hand of 19 (61.3\%) patients in the DF group and $11(35.5 \%)$ patients in the PF group.

There was no stiffness of fingers and wrist in 25 (80.6\%) and $20(64.5 \%)$ patients of the DF and PF group respectively. Nondisabling type of median nerve injury was observed in only 3 (9.7\%) patients of the PF group $(p=0.238)$. Arthritic changes and tendon injuries were not noted in any of the patients in both groups.

SAITO score:

At twelve weeks follow-up, 29(93.5\%) patients in the DF group and $22(71.0 \%)$ patients in the PF group had good to excellent results as shown in Table 3.

\section{DISCUSSION}

Colles' fracture is one of the commonest fractures among the elderly populace. In our study, there were more female patients, which were similar to a study conducted by Gnawali G P in Lumbini zonal hospital, Nepal. ${ }^{8}$ The reason for this may be the direct relationship of Colles' fracture and osteoporosis in the female population, where they are more prone to fall on an outstretched hand while doing domestic chores rather than on a road traffic accident. Colles' fractures can be difficult to treat and there remains no absolute consensus on the best method for treatment. Conservative management can be a safer option giving an acceptable clinical outcome. ${ }^{11}$ Sarmentio advocated immobilizations in the position of supination to decrease the deforming force of the brachioradialis, which may cause loss of reduction. ${ }^{12,13}$ In contrast, Wahlstrom recommended immobilization in pronation because he claimed pronator quadratus as a deforming force which is responsible for the loss of reduction. ${ }^{14}$ 
Table 2: Radiological parameters of radial tilt, palmar tilt, and ulnar variance at the time of presentation and in successive follow-ups

\begin{tabular}{|c|c|c|c|c|c|c|c|c|c|c|}
\hline & \multicolumn{2}{|c|}{ Pre reduction } & \multicolumn{2}{|c|}{ Post reduction } & \multicolumn{2}{|l|}{$1^{\text {st }}$ week } & \multicolumn{2}{|l|}{$6^{\text {th }}$ week } & \multicolumn{2}{|c|}{$12^{\text {th }}$ week } \\
\hline & DF & PF & DF & PF & DF & PF & DF & PF & DF & $\mathrm{PF}$ \\
\hline \multicolumn{11}{|l|}{ Radial Tilt } \\
\hline$<13^{\circ}$ & $\begin{array}{l}19 \\
(61.3 \%)\end{array}$ & $\begin{array}{l}14 \\
(45.2 \%)\end{array}$ & 0 & 0 & 0 & 0 & 0 & $\begin{array}{l}1 \\
(3.2 \%)\end{array}$ & $\begin{array}{l}1 \\
(3.2 \%)\end{array}$ & $\begin{array}{l}5 \\
(16.1 \%)\end{array}$ \\
\hline $13^{\circ}-33^{\circ}$ & 12 & $\begin{array}{l}17 \\
(54.8 \%)\end{array}$ & $\begin{array}{l}31 \\
(100 \%)\end{array}$ & $\begin{array}{l}31 \\
(100 \%)\end{array}$ & $\begin{array}{l}31 \\
(100 \%)\end{array}$ & $\begin{array}{l}31 \\
(100 \%)\end{array}$ & $\begin{array}{l}31 \\
(100 \%)\end{array}$ & $\begin{array}{l}30 \\
(96.8 \%)\end{array}$ & $\begin{array}{l}30.271 \\
(96.8 \%)\end{array}$ & $\begin{array}{l}26 \\
(83.9 \%)\end{array}$ \\
\hline$>33^{\circ}$ & 0 & 0 & 0 & 0 & 0 & 0 & 0 & 0 & 0 & 0 \\
\hline Total & $\begin{array}{l}31 \\
(100 \%)\end{array}$ & $\begin{array}{l}31 \\
(100 \%)\end{array}$ & $\begin{array}{l}31 \\
(100 \%)\end{array}$ & $\begin{array}{l}31 \\
(100 \%)\end{array}$ & $\begin{array}{l}31 \\
(100 \%)\end{array}$ & $\begin{array}{l}31 \\
(100 \%)\end{array}$ & $\begin{array}{l}31 \\
(100 \%)\end{array}$ & $\begin{array}{l}31 \\
(100 \%)\end{array}$ & $\begin{array}{l}31 \\
(100 \%)\end{array}$ & $\begin{array}{l}31 \\
(100 \%)\end{array}$ \\
\hline \multicolumn{11}{|l|}{ Palmar Tilt } \\
\hline$<1^{\circ}$ & $\begin{array}{l}30 \\
(96.8 \%)\end{array}$ & $\begin{array}{l}24 \\
(77.4 \%)\end{array}$ & 0 & 0 & 0 & 0 & $\begin{array}{l}1 \\
(3.2 \%)\end{array}$ & $\begin{array}{l}10 \\
(32.3 \%)\end{array}$ & $\begin{array}{l}4 \\
(12.9 \%)\end{array}$ & $\begin{array}{l}12 \\
(38.7 \%)\end{array}$ \\
\hline $1^{\circ}-21^{\circ}$ & $(3.2 \%)$ & $(22.6 \%)$ & $\begin{array}{l}31 \\
(100 \%)\end{array}$ & $\begin{array}{l}31 \\
(100 \%)\end{array}$ & $\begin{array}{l}31 \\
(100 \%)\end{array}$ & $\begin{array}{l}31 \\
(100 \%)\end{array}$ & $\begin{array}{l}30 \\
(96.8 \%)\end{array}$ & $(67.7 \%)$ & $\begin{array}{l}27 \\
(87.1 \%)\end{array}$ & $\begin{array}{l}19 \\
(61.3 \%)\end{array}$ \\
\hline$>21^{\circ}$ & 0 & 0 & 0 & 0 & 0 & 0 & 0 & 0 & 0 & 0 \\
\hline Total & $\begin{array}{l}31 \\
(100 \%)\end{array}$ & $\begin{array}{l}31 \\
(100 \%)\end{array}$ & $\begin{array}{l}31 \\
(100 \%)\end{array}$ & $\begin{array}{l}31 \\
(100 \%)\end{array}$ & $\begin{array}{l}31 \\
(100 \%)\end{array}$ & $\begin{array}{l}31 \\
(100 \%)\end{array}$ & $\begin{array}{l}31 \\
(100 \%)\end{array}$ & $\begin{array}{l}31 \\
(100 \%)\end{array}$ & $\begin{array}{l}31 \\
(100 \%)\end{array}$ & $\begin{array}{l}31 \\
(100 \%)\end{array}$ \\
\hline \multicolumn{11}{|c|}{ Ulnar Variance } \\
\hline$<-2 \mathrm{~mm}$ & 0 & $\mathrm{O}$ & 0 & 0 & 0 & 0 & 0 & 0 & 0 & $\begin{array}{l}1 \\
(3.2 \%)\end{array}$ \\
\hline $\begin{array}{l}-2 \mathrm{~mm} \text { to } \\
+2 \mathrm{~mm}\end{array}$ & $\begin{array}{l}1 \\
(3.2 \%)\end{array}$ & $\begin{array}{l}10 \\
(32.3 \%)\end{array}$ & $\begin{array}{l}31 \\
(100 \%)\end{array}$ & $\begin{array}{l}31 \\
(100 \%)\end{array}$ & $\begin{array}{l}31 \\
(100 \%)\end{array}$ & $\begin{array}{l}31 \\
(100 \%)\end{array}$ & $\begin{array}{l}24 \\
(77.4 \%)\end{array}$ & $\begin{array}{l}17 \\
(54.8 \%)\end{array}$ & $\begin{array}{l}15 \\
(48.4 \%)\end{array}$ & $\begin{array}{l}(3.2 \%) \\
9 \\
(29.0 \%)\end{array}$ \\
\hline$>+2 \mathrm{~mm}$ & $\begin{array}{l}30 \\
(96.8 \%)\end{array}$ & $\begin{array}{l}21 \\
(67.7 \%)\end{array}$ & 0 & 0 & 0 & 0 & 7 & 14 & 16 & 21 \\
\hline Total & $\begin{array}{l}31 \\
(100 \%)\end{array}$ & $\begin{array}{l}31 \\
(100 \%)\end{array}$ & $\begin{array}{l}31 \\
(100 \%)\end{array}$ & $\begin{array}{l}31 \\
(100 \%)\end{array}$ & $\begin{array}{l}31 \\
(100 \%)\end{array}$ & $\begin{array}{l}31 \\
(100 \%)\end{array}$ & $\begin{array}{l}31 \\
(100 \%)\end{array}$ & $\begin{array}{l}31 \\
(100 \%)\end{array}$ & $\begin{array}{l}31 \\
(100 \%)\end{array}$ & $\begin{array}{l}31 \\
(100 \%)\end{array}$ \\
\hline
\end{tabular}

Table 3. The outcome of Saito's scoring system

\begin{tabular}{|c|c|c|c|c|c|c|}
\hline \multirow{2}{*}{ SAITO } & \multicolumn{2}{|c|}{$6^{\text {TH }}$ week } & \multirow{2}{*}{$p$-value } & \multicolumn{2}{|c|}{$12^{\mathrm{TH}}$ week } & \multirow{2}{*}{ p-value } \\
\hline & DF & PF & & DF & PF & \\
\hline Excellent & 0 & 0 & \multirow{5}{*}{0.036} & 20 (64.5\%) & $7(22.6 \%)$ & \multirow{5}{*}{0.003} \\
\hline Good & $15(48.4 \%)$ & $7(22.6 \%)$ & & $9(29.0 \%)$ & 15 (48.4\%) & \\
\hline Fair & $14(45.2 \%)$ & $16(51.6 \%)$ & & $2(6.5 \%)$ & $8(25.8 \%)$ & \\
\hline Poor & $2(6.5 \%)$ & $8(25.8 \%)$ & & 0 & $1(3.2 \%)$ & \\
\hline Total & $31(100 \%)$ & 31 (100\%) & & $31(100 \%)$ & 31 (100\%) & \\
\hline
\end{tabular}


According to John Charnley, ${ }^{15}$ Colles' fracture should be treated by closed reduction, cast immobilization in palmar flexion, and ulnar deviation as the dorsal periosteal hinge provides stability. But this conventional position has a higher chance of re displacement, inhibits hand functions and has greater associated complications like median nerve compression. ${ }^{16}$

In our study, we compared the radiological and functional results of Colles' fractures treated conservatively in two groups, one with wrist immobilized in DF and the other in PF. During the early follow-ups radial tilt (RT), palmar tilt (PT), and ulnar variance (UV) were well maintained within the normal range in both the groups. But at twelve weeks follow up DF immobilized group had more number of patients in the normal range as compared to patients in PF immobilized group [RT: $D F=30(96.8 \%) \quad P F=26(83.9 \%), P T: D F=27(87.1 \%)$ $\mathrm{PF}=19(61.3 \%), \mathrm{UV}$ : $\mathrm{DF}=15(48.4 \%) \mathrm{PF}=9(29.0 \%)]$. Thus residual deformity seemed to be greater in the PF immobilized group which was similar to a study conducted by Rajan $\mathrm{S}$ et al. ${ }^{16}$

Comparing the radiological parameters at 6 and 12 weeks, UV was lost to a maximum number of patient in both the study group ( $D F=9, P F=6)$ followed by $P T(D F=3, P F=2)$ and $R T(D F=1$, $\mathrm{PF}=4$ ) which was proportionate to a study conducted by Rajan $\mathrm{S}$ et al. ${ }^{16}$ This subsequent loss of reduction may be due to more female patients $43(69.4 \%)$ in our study who are more likely to have an osteoporotic bone. ${ }^{17}$ But in a study done by Gnawali G P et al did not show any loss of reduction in successive follow up. ${ }^{8}$

The functional result in our study involving the individual movements of dorsiflexion, palmar flexion, supination, pronation, ulnar, and radial deviation at twelve weeks of follow up was significantly better when the wrist was immobilized in DF. This result was also comparable with the study done by Gupta $A$ in which Colles' fractures were reduced and immobilized with the wrist in three different positions: Palmar flexion, neutral, or dorsiflexion. ${ }^{18}$ They reported that in displaced extra-articular fractures with no comminution the position of wrist made no significant difference. But in comminuted fractures, the best anatomical results were in fractures treated in dorsiflexion. Functional results in all fractures, regardless of the classification were superior if the fractures were treated in dorsiflexion. The reason could be understood by understanding the biomechanics of the wrist joint and fracture reduction. In the PF group, the dorsal carpal ligament is taut, but cannot stabilize the fracture because of its lack of attachment to the distal carpal row. Thus the deforming forces applied in the line of palmar flexed wrist acts in a parallel manner which tends to displace the fracture. While in DF immobilized wrist the volar ligament is taut which has an attachment to the distal as well as proximal carpal row and tends to pull the fracture anteriorly. Here, the deforming forces act at an angle that tends to reduce the displacement of the fracture thus preventing re-displacement as shown in figure $2 .{ }^{18}$ In a grossly comminuted fracture some collapse is probably inevitable, but this is likely to be minimized when the wrist is immobilized in dorsiflexion. Figure 3 shows collapse or impaction of the dorsal cortex inside a straight or smoothly curved tube than in a tube with a double curve or ' $\mathrm{S}$ ' shape. ${ }^{18}$

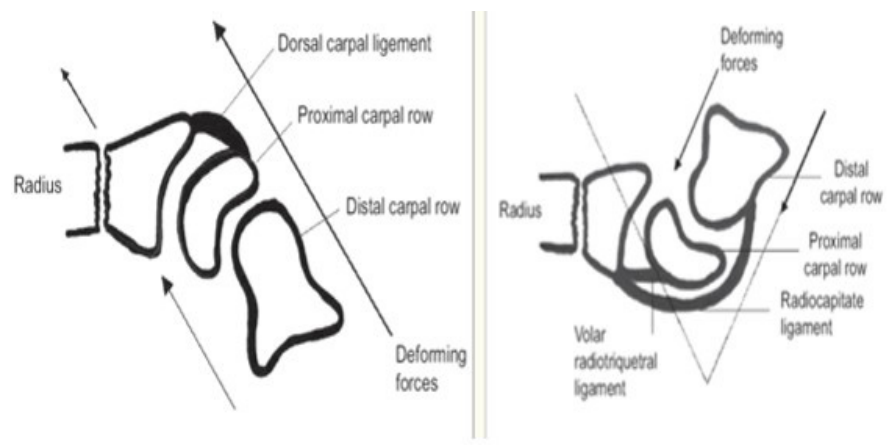

Figure 2: Stability of fracture in two different positions ${ }^{16}$
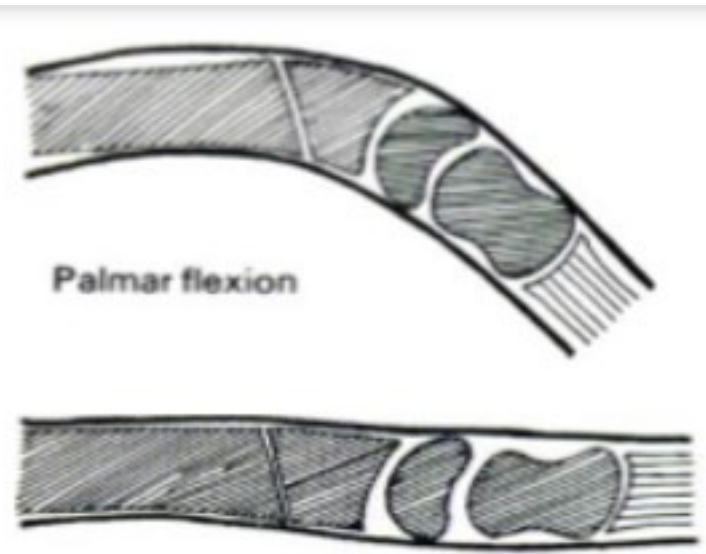

Neutral

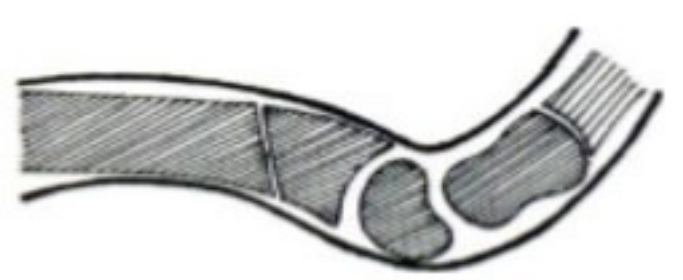

Dorsiflexion

Figure 3: Straight and curve tube phenomenon concerning fracture collapse ${ }^{18}$

Hand dominance is an important factor in the treatment of Colles' fracture. Elderly patients might not need too much power in their non-dominant hand, nor do they use the non-dominant hand frequently after trauma. ${ }^{7}$ Therefore grip power was one of the most important factors in achieving a good subjective evaluation in patients with the fractured dominant hand. In our study majority of the patient in both the groups were right hand dominant [(DF=30(96.8\%), PF= 29(93.5\%)] and in contrast to it, the majority of fractures involved the left side (nondominant) in both the groups [DF=20(64.5\%) PF=20(64.5)]. Therefore, a good result in our study may be due to more involvement of fracture in a non-dominant hand which least bothered the patients.

Furthermore, comparing the grip power among the two groups at the twelfth week showed normal as well as faster recovery 
in DF immobilized group as compared to PF immobilized group, $19(61.3 \%)$ and $11(35.5 \%)$ patients respectively. The reason for early recovery in extended (DF) wrist may be due to its optimal position for function and rehabilitation. ${ }^{19}$

Median nerve paresis of non-disabling type was the single most complication noted at 12 weeks of follow up in 3(9.7\%) patients in PF group, which was similar to a study conducted by Cooney WP at el stating median nerve compression as the commonest complication of Colles' fracture accounting $7.9 \%$, which may be the result of the loss of reduction at fracture site. ${ }^{20}$

Using Saito's scoring system, at twelve weeks, the number of good to excellent patients were $29(93.5 \%)$ in DF immobilized group and $22(71.0 \%)$ in PF immobilized group ( $p=0.003$ ) which was similar to a study conducted by Rajan $\mathrm{S}^{16}$ showing $31(91.7 \%)$ patients in DF immobilized group and $20(66.6 \%)$ patients in PF immobilized group. Thus, both the studies showed

\section{REFERENCES:}

1. Colles A. On the fracture of the carpal extremity of the radius. Edinb Med Sur J. 1814;10:182-6. [PMID]

2. Golden GN. Treatment and prognosis of Colles' fracture. Lancet. 1963;1:511-14. [PMID]

3. Gartland JJ Jr, Werley CW. Evaluation of healed Colles' fracture. J Bone Joint Surg Am.1951;33-A(4):895-907. [PMID]

4. Gliatis, JD, Plessas SJ, Davis TR. The outcome of distal radial fractures in young adults. J Hand Surg 2000;25:535. [PMID]

5. Bajracharya $S$, Singh $S$, Singh GK, Singh $M$, Bajracharya T. The efficacy of the hematoma block for fracture reduction in the distal forearm fractures: a double blind randomized controlled trial. Int J Anesthesiol. 2008;17(2). [LINK]

6. Shaikh SI, Basit A, Iqbal J. Treatment of Colles' fracture with wrist immobilization in palmar flexed and dorsiflexed position. JIMMC.2012;7(1):26-34. [LINK]

7. Fujii K, Henmi T, Kenematsu Y, Mishiro T, Sakai T, Terai T. Fractures of distal end of radius in elderly patients: A comparative study of anatomical and functional results. J Orthop Surg (Hong Kong). 2002;10(1):9-15. [DOI]

8. Gnawali GP. Comparative study of radiological and functional outcome of extra-articular distal radius fracture treated conservatively with respect to its position of immobilization. Journal of Universal College of Medical Sciences. 2018;6(1):46-51. [DOI]

9. Saito $\mathrm{H}$, Shibata $\mathrm{M}$. Classification of fracture at the distal end of the radius with reference to treatment of comminuted fractures. In: Boswick JA, editor. Current Concepts in Hand Surgery. Philadelphia, Pa, USA: Lea\&Febiger; 1983. pp. 129-45.

10. Denby K, Nelson G, Estrada CA. Bedside hand grip assessment with the more number of patients in the DF group to be in the good to excellent category.

The limitation of this study was a smaller sample size with a short follow up. This is a single centre study so the study results cannot be generalized.

\section{CONCLUSION}

In a conservatively treated Colles' fracture, flexion should be maintained at the fracture site to make use of periosteal hinge but the wrist should be immobilized in a position of slight dorsiflexion to achieve a better functional and radiological outcome. This position also enhances the rehabilitation of the fingers and wrist.

\section{CONFLICT OF INTEREST: None}

\section{FINANCIAL DISCLOSURE: None}

sphygmomanometer. J Gen Intern Med. 2013;28(10):1381. [DOI]

11. Blakeney WG. Stabilization and treatment of Colles' fractures in elderly patients. Clin Interv Aging.2010;5:337-44. [DOI]

12. Sarmentio A, Latta LL. The evolution of functional bracing of fractures .J Bone Joint Surg Br 1995;88(2):141-8. [DOI]

13. Sarmiento A, Zagorski JB, Sinclair WF. Functional bracing of Colles' fractures: A prospective study of immobilization in supination vs. pronation. Clin Orthop Relat Res. 1980;146:175-83. [PMID]

14. 1Wahlstrom O. Treatment of Colles' fracture. A prospective comparison of three different positions of immobilization. Acta Orthop Scand. 1982;53(2):225-28. [DOI]

15. Charnley J. The Colles' fracture: The closed treatment of common fractures, 4th ed, Vol 4,1999.p.128-42.

16. Rajan S, Jain S, Ray A, Bhargava P. Radiological and functional outcome in extra articular fracture of lower end radius treated conservatively with respect to its position of immobilization. Indian J Orthop.2008;42(2):201-207. [PMID]

17. Shrestha S, Dahal S, Bhandari P, Bajracharya S, Marasini A. Prevalence of osteoporosis among adults in a tertiary care hospital: a descriptive cross-sectional study. Journal of Nepal Medical Association. 2019;57(220):393-7. [DOI]

18. Gupta A. The treatment of Colles' fracture Immobilization with the wrist in dorsiflexion. J Bone Joint Surg Br. 1991;73(2): 312-5. [PMID]

19. Baruah RK, Islam M, Haque R. Immobilisation of extra-articular distal radius fracture (Colles' type ) in dorsiflexion. The functional and anatomical outcome. J Clin Orthop Trauma .2015;6(3):167-72. [DOI]

20. Cooney WP 3rd, Dobyns JH, Linscheid RL. Complication of Colles' fracture. J Bone Joint Surg Am.1980;62(4):613-9. [PMID] 